\title{
Impact of the antifungal protein PgAFP from Penicillium chrysogenum on the protein profile in Aspergillus flavus
}

\author{
Josué Delgado $^{1} \cdot$ Rebecca A. Owens $^{2} \cdot$ Sean Doyle ${ }^{2} \cdot$ Miguel A. Asensio $^{1} \cdot$ Félix Núñez $^{1}$
}

Received: 25 February 2015 /Revised: 24 May 2015 / Accepted: 27 May 2015 /Published online: 16 June 2015

(C) Springer-Verlag Berlin Heidelberg 2015

\begin{abstract}
Antifungal proteins produced by molds are generally small, highly basic, and cysteine-rich. The best known effects of these proteins include morphological changes, metabolic inactivation, and membrane perturbation on sensitive fungi. Reactive oxygen species (ROS) generation leads to apoptosis, with $\mathrm{G}$-protein playing a key role in transduction of cell death signals. The antifungal protein PgAFP from Penicillium chrysogenum inhibits growth of some toxigenic molds. Here we analyzed the effect of the antifungal protein PgAFP on the growth of Aspergillus flavus. For this, comparative proteomic analysis was used to identify the whole protein profile and protein change in abundance after PgAFP treatment. PgAFP provoked metabolic changes related to reduced energy metabolism, cell wall integrity alteration, and increased stress response due to higher levels of ROS. The observed changes in protein abundance, favoring a higher glutathione concentration as well as the increased abundance in heat shock proteins, do not seem to be enough to avoid necrosis. The decreased chitin deposition observed in PgAFP-treated $A$. flavus is attributed to a lower relative quantity of Rho1. The reduced relative abundance of a $\beta$ subunit of $\mathrm{G}$-protein seems to be the underlying reason for modulation of apoptosis in PgAFP-treated A. flavus hyphae. We propose
\end{abstract}

Electronic supplementary material The online version of this article (doi:10.1007/s00253-015-6731-x) contains supplementary material, which is available to authorized users.

Miguel A. Asensio

masensio@unex.es

1 Food Hygiene and Safety, Institute of Meat Products, University of Extremadura, Cáceres, Spain

2 Department of Biology, Maynooth University, Maynooth, Co. Kildare, Ireland
Rho1 and $\mathrm{G}$-protein subunit $\beta \mathrm{CpcB}$ to be the main factors in the mode of action of PgAFP in A. flavus. Additionally, enzymes essential for the biosynthesis of aflatoxin were no longer detectable in A. flavus hyphae at $24 \mathrm{~h}$, following treatment with PgAFP. This presents a promising effect of PgAFP, which may prevent $A$. flavus from producing mycotoxins. However, the impact of PgAFP on actual aflatoxin production requires further study.

Keywords Antifungal compounds · Toxigenic fungi · Aspergillus flavus $\cdot$ Apoptosis $\cdot$ Proteomics

\section{Introduction}

Antimicrobial proteins are produced by different organisms throughout all kingdoms (Leiter et al. 2005). Some antifungal proteins produced by molds are small, highly basic, and cysteine-rich proteins, such as PAF from Penicillium chrysogenum Q176 (Marx et al. 1995), PgAFP from $P$. chrysogenum RP42C (Rodríguez-Martín et al. 2010), PcArctin from P. chrysogenum A096 (Chen et al. 2013), AFP from Aspergillus giganteus (Nakaya et al. 1990), or NAFP from Neosartorya fischeri (Kovács et al. 2011). The expression of these proteins is induced in the presence of other fungi and contributes to an ecological advantage (Marx 2004). Antifungal proteins produced by molds may serve to combat unwanted molds. Toxigenic molds are among the main hazards in intermediate moisture foods, with the aflatoxin producer Aspergillus flavus being one of the main concerns. The mechanism of action of antifungal proteins seems to be multifactorial, leading to morphological changes, metabolic inactivation, or membrane perturbation in a dose-dependent manner (Kaiserer et al. 2003). The site of action on sensitive molds does not share the same pattern among antifungal proteins. 
PAF penetrates into the cytoplasm (Oberparleiter et al. 2003; Batta et al. 2009); AFP showed co-localization with the nucleus in Magnaporthe grisea (Moreno et al. 2006), while it is bound mainly to cell wall in Aspergillus niger (Theis et al. 2003, 2005). Membrane permeabilization could be involved in the mechanism of action. Some non-fungal antimicrobial proteins destabilize membranes by pore formation, whereas PAF induces a selective permeability to potassium (Kaiserer et al. 2003; Marx et al. 2008). In addition, PAF and NAFP induce oxidative stress in sensitive fungi, with elevated levels of reactive oxygen species (ROS) being the main effect contributing to apoptosis (Leiter et al. 2005; Galgóczy et al. 2013). It has been proposed that $G$ protein is responsible for the transduction of PAF-initiated apoptotic cell death signals (Leiter et al. 2005). This is achieved through modulation of the intracellular glutathione (GSH) and ROS levels in Aspergillus nidulans (Hegedus et al. 2011). Here we used PgAFP, one of these small, basic, and cysteine-rich proteins that inhibits growth of some toxigenic molds (RodríguezMartín et al. 2010), to study the effect on the growth of $A$. flavus. Among the possible effects derived from antifungal proteins on A. flavus, those related to aflatoxin biosynthesis would be of interest for practical applications. P. chrysogenum RP42C isolated from dry-cured ham produces PgAFP and was used here as a source of the antifungal protein.

The mechanism of action of PgAFP on sensitive molds is unknown, and elucidation of this mechanism would allow the evaluation of potential applications for PgAFP. Comparative proteomic analysis constitutes a valuable tool to explore the effect of PgAFP on sensitive molds, which may provide rewarding information to exploit the practical use against toxigenic molds. Comparative proteomic analyses have been used in previous studies to explore the effect of some substances, such as $\mathrm{H}_{2} \mathrm{O}_{2}$, on molds (Lessing et al. 2007), and to identify resistance to antifungal drugs (Gautam et al. 2008; Cagas et al. 2011). Comparative proteomic 2D-PAGE has the capability to separate proteins in high resolution, even those including posttranslational modifications. We used this technique to identify 23 unique proteins, identified from protein spots that showed a significant change in abundance in A. flavus in response to PgAFP. However, this technique only reveals a small percentage of the whole proteome depending on the range of $\mathrm{pH}$ (Görg et al. 2009), and it is not optimal for the analysis of membrane and hydrophobic proteins (Rabilloud et al. 2009). These features lead to several proteins under-represented on 2D-PAGE. Label-free quantitative proteomics can be used to examine those proteins not analyzable by 2D-PAGE. Therefore, a second proteomic approach, involving labelfree proteomics, was used to analyze the proteome quantitatively and qualitatively.

The results of comparative proteomics informed on the mechanisms and systems affected by the antifungal compound in a sensitive mold. Information generated was subsequently used to select adequate tests to confirm the changes attributed to proteins whose relative abundance is affected. The objective of the present work has been to study the effect of PgAFP on the proteomic profile and the structural and metabolic changes caused in A. flavus, a fungus that produces aflatoxins in foods.

\section{Material and methods}

\section{Strains}

In vitro tests were carried out with the PgAFP producer $P$. chrysogenum strain RP42C (CECT 20922) that resists at least $312.7 \mu \mathrm{g} / \mathrm{ml} \mathrm{PgAFP}$ (Delgado et al. 2015), and A. flavus (CECT 2687), both from the Spanish Type Culture Collection (CECT). The latter strain produces aflatoxins in dry-cured ham (Bernáldez et al. 2014).

\section{Purification of PgAFP}

P. chrysogenum was grown in potato dextrose broth (PDB; Scharlab, Barcelona, Spain) $\mathrm{pH} 4.5$, at $25^{\circ} \mathrm{C}$ for 21 days. Mycelium was removed and the culture medium was filtered through a nitrocellulose $0.22-\mu \mathrm{m}$ pore size (Sartorius, Goettingen, Germany) to obtain cell-free medium. The cellfree medium was applied to an ÄKTA FPLC with a cationic exchange column HiTrap SP HP (Amersham Biosciences, Uppsala, Sweden), equipped with a UV detector at $214 \mathrm{~nm}$. The resulting fraction containing PgAFP was then chromatographed on a HiLoad 26/60 Superdex 75 column for FPLC (Amersham Biosciences, Uppsala, Sweden) as previously described (Acosta et al. 2009) to obtain an extract of the purified protein. The extract containing the purified PgAFP from several batches were pooled in a stock solution. The amount of protein in the stock solution was quantified by the Lowry method (Lowry et al. 1951). For the various assays, the PgAFP stock solution was diluted to the desired active concentration range according to the aim of the test.

\section{Protein extraction}

A. flavus CECT 2687 was cultured in triplicate in 50-ml PDB, at $25{ }^{\circ} \mathrm{C}$ with shaking at $200 \mathrm{rpm}$, in either presence $(10 \mu \mathrm{g} / \mathrm{ml})$ or absence of PgAFP for $24 \mathrm{~h}$. Mycelia were harvested, filtered, washed, and lysed as described previously (Carberry et al. 2006). Mycelial lysates were centrifuged $(10,000 \times g ; 30 \mathrm{~min})$ to remove cell debris and the subsequent supernatant precipitated with trichloroacetic acid/acetone (Carpentier et al. 2005). From these precipitated lysates, the two following proteomic analysis were carried out. Additionally, to confirm that cultures were in the exponential growth phase, growth in 24- to 48-h cultures was estimated by 
mycelium dry weight determination at $100{ }^{\circ} \mathrm{C}$ to a constant weight.

\section{Two-dimensional PAGE}

For protein separation by 2D-PAGE, resuspended extracts containing $250 \mu \mathrm{g}$ of protein were loaded onto Immobiline Dry strips (IPG strip; Amersham Biosciences) in the $\mathrm{pH}$ range 4-7, followed by electrofocusing, and electrophoresis using the Protean Xi-II Cell (Bio-Rad Laboratories) as described previously (Carberry et al. 2006). Resulting gels (three biological replicates and two technical replicates per treatment) were stained with colloidal Coomassie Blue (Sigma-Aldrich, St. Louis, MO, USA), scanned, and analyzed using Progenesis ${ }^{\mathrm{TM}}$ SameSpot software (TotalLab, Newcastle, UK) (O'Keeffe et al. 2013; Collins et al. 2013; Owens et al. 2014). Spot intensities were normalized in Progenesis SameSpot software using the total spot volume normalization method prior to comparative analysis, to correct for any variation in protein loading, staining/destaining, or image acquisition. Protein spots showing differences $(p<0.05$, fold change $\geq 1.5$ ) were excised and in-gel digested as described previously (Shevchenko et al. 2006). Briefly, selected spots were destained by addition of $100 \mu \mathrm{l}$ of $100 \mathrm{mM}$ ammonium bicarbonate:acetonitrile $(1: 1 \mathrm{v} / \mathrm{v})$ for $30 \mathrm{~min}$. Acetonitrile $(500 \mu \mathrm{l})$ was added to samples to dehydrate the gel pieces, then discarded and replaced with $50 \mu \mathrm{l}$ of trypsin $(13 \mathrm{ng} / \mu \mathrm{l})$. Samples were incubated at $4{ }^{\circ} \mathrm{C}$ for $2 \mathrm{~h}$ followed by overnight incubation at $37^{\circ} \mathrm{C}$. Then, samples were sonicated for $10 \mathrm{~min}$, and the digested supernatant was transferred to clean tubes to be completely dried using a DNA Speed Vac Concentrator (Thermo Fischer Scientific, Austin, TX, USA) and resuspended in $0.1 \%$ formic acid (FA; $20 \mu \mathrm{l})$. The samples were filtered through $0.22-\mu \mathrm{m}$ cellulose spin filters (Agilent Technologies, Dublin, Ireland). The samples were analyzed by a 6340 Model Ion Trap LC-Mass Spectrometer (Agilent Technologies, Dublin, Ireland) using electrospray ionization. Samples $(3 \mu \mathrm{l})$ were loaded onto a Zorbax 300 SB C-18 Nano-HPLC Chip $(150 \mathrm{~mm} \times 75 \mu \mathrm{m})$ with $0.1 \%(v / v)$ FA at a flow rate of a $4 \mu \mathrm{l} / \mathrm{min}$. The eluted peptides were ionized and analyzed by mass spectrometry. $\mathrm{MS}^{\mathrm{n}}$ analysis was carried out on the three most abundant peptide precursor ions at each time point, as selected automatically by the mass spectrometer. MASCOT MS/MS ion search, National Centre for Biotechnology Information (NCBI; www.ncbi.nlm.nih.gov/guide/proteins/) database, and Kyoto Encyclopedia of Genes and Genomes (KEGG; www.genome.jp/kegg/) were used for protein identification and function.

\section{Label-free comparative quantitative proteomic analysis}

The protein precipitated lysates, from 3 biological replicates per treatment, were resuspended in $8 \mathrm{M}$ urea. After dithiothreitol reduction and iodoacetic acid-mediated alkylation (Owens et al. 2014), sequencing-grade trypsin combined with ProteaseMax surfactant was added. Digested samples were desalted prior to analysis using C18 ZipTips ${ }^{\circledR}$ (Millipore, Darmstadt, Germany). A quantity $(1 \mu \mathrm{g})$ was analyzed from each digest, a Q-Exactive mass spectrometer coupled to a Dionex RSLCnano (Thermo Scientific, Waltham, MA, USA). LC gradients ran from 4 to $35 \% \mathrm{~B}$ (A: $0.1 \%$ FA, B: $80 \%$ acetonitrile, $0.1 \%$ FA) over $2 \mathrm{~h}$, and data was collected using a Top15 method for MS/MS scans (Dolan et al. 2014; O'Keeffe et al. 2014). Comparative proteome abundance and data analysis was performed using MaxQuant software (Version 1.3.0.5; www.maxquant.org/ downloads.htm) (Cox and Mann 2008), with Andromeda used for database searching and Perseus (Version 1.4.1.3) used to organize the data. Carbamidomethylation of cysteines was set as a fixed modification, while oxidation of methionines and acetylation of N-terminals were set as variable modifications. The maximum peptide/protein false discovery rates (FDR) were set to $1 \%$ based on comparison to a reverse database. The LFQ algorithm was used to generate normalized spectral intensities and infer relative protein abundance (Luber et al. 2010). Proteins that matched to a contaminant database or the reverse database were removed, and proteins were only retained in final analysis if detected in at least two replicates from at least one treatment. Quantitative analysis was performed using a $t$ test to compare pairs of samples. Due to the high sensitivity and larger dynamic range of the gel-free proteomics analyses, only proteins with a fold change $\geq 2(p<0.05)$ were included in the quantitative results (Table S1 in the Supplementary Material) (Dolan et al. 2014; O'Keeffe et al. 2014). Qualitative analysis was also performed to detect proteins that were found in at least two replicates of a particular sample but undetectable in the comparison sample (Table S1 in the Supplementary Material).

\section{Effect of PgAFP on A. flavus growth}

The growth of PgAFP-treated A. flavus was evaluated on microtiter plates (DeltaLab, Rubí, Spain), with $200 \mu \mathrm{l}$ of PDB and $10^{5}$ conidia per well incubated at $25^{\circ} \mathrm{C}$ during $96 \mathrm{~h}$ in static conditions. Seven serial 1:2 dilutions of PgAFP (i.e., 75, $37.5,18.75,9.38,4.69,2.34$, and $1.17 \mu \mathrm{g} / \mathrm{ml})$ and a nontreated control were assayed. Optical density was measured at $550 \mathrm{~nm}$ every $24 \mathrm{~h}$ in an Infinite M2000 microplate reader (TECAN, Männedorf, Switzerland).

\section{SYTOX Green uptake}

A. flavus was grown and treated with the seven PgAFP concentrations from 75 to $1.17 \mu \mathrm{g} / \mathrm{ml}$ described above. Additionally, $P$. chrysogenum was also used as a resistant control. After incubation of test samples for $24 \mathrm{~h}$ at $25^{\circ} \mathrm{C}$, 
wells were supplemented with $0.2 \mu \mathrm{M}$ SYTOX Green (Molecular Probes, Eugene, OR, USA). The fluorescence emitted was measured at 10, 30, and $210 \mathrm{~min}$ in an Infinite M2000 spectrophotometer (TECAN, Männedorf, Switzerland), with excitation wavelength of $480 \mathrm{~nm}$ (slit, $5 \mathrm{~nm}$ ) and emission wavelength of $530 \mathrm{~nm}$ (slit, $10 \mathrm{~nm}$ ).

\section{Hyphal morphology}

A. flavus was grown in tubes containing $300 \mu \mathrm{l}$ of PDB at $25^{\circ} \mathrm{C}$ for $24 \mathrm{~h}$ in either presence $(20$ and $75 \mu \mathrm{g} / \mathrm{ml})$ or absence of PgAFP. Mycelium was collected by centrifugation and observed on a microscope Eclipse E200 equipped with a digital camera DS-Fi2 (Nikon, Tokyo, Japan).

\section{FUN-1 staining}

To evaluate the metabolic activity with a viability staining, the mycelium of $A$. flavus in either presence $(20 \mu \mathrm{g} / \mathrm{ml})$ or absence of PgAFP was washed with 10 mM HEPES (pH 7.5) before staining with $100 \mu \mathrm{FUN}-1$ (Molecular Probes, Eugene, OR, USA) for $30 \mathrm{~min}$ at $25^{\circ} \mathrm{C}$ as described previously (Kaiserer et al. 2003). The PgAFP producer strain $P$. chrysogenum was used as a resistant control. Stained hyphae were examined and photographed by fluorescence microscopy (Nikon, Tokyo, Japan).

\section{Chitin staining}

Conidia of A. flavus were inoculated on 10-ml PDB in a Petri dish containing a cover glass and incubated in presence (20 and $75 \mu \mathrm{g} / \mathrm{ml}$ ) and absence of PgAFP at $25^{\circ} \mathrm{C}$ for $24 \mathrm{~h}$ (Harris et al. 1994). Similarly, as a control, $P$. chrysogenum was treated with $75 \mu \mathrm{g} / \mathrm{ml}$ PgAFP. Mycelium was fixed and stained for 5 min with fluorescent brightener 28 (Sigma-Aldrich, St. Louis, MO, USA) and then washed to visualize chitin in a fluorescence microscopy with an excitation wavelength of $387 / 11 \mathrm{~nm}$.

\section{Nuclei staining}

To visualize the distribution of nuclei in PgAFP-treated (20 and $75 \mu \mathrm{g} / \mathrm{ml}$ ) and non-treated hyphae, double-stranded DNA was fluorescently labeled by incubating with $1.6 \mu \mathrm{M}$ Hoechst 33258 dye (Molecular Probes, Eugene, OR, USA) for $30 \mathrm{~min}$ at $25{ }^{\circ} \mathrm{C}$ as described previously (Kaiserer et al. 2003) and visualized through fluorescence microscopy with excitation wavelength of $387 / 11 \mathrm{~nm}$.

\section{Localization of FITC-labeled PgAFP}

PgAFP was labeled by DareBio S.L. (Elche, Spain). For this, $100 \mu \mathrm{l}$ of $20 \mathrm{mM}$ fluorescein isothiocyanate (FITC; Anaspec,
Fremont, CA, USA) in dimethyl sulfoxide was added to $4 \mathrm{ml}$ of PgAFP $(369 \mu \mathrm{g} / \mathrm{ml})$ and left for $8 \mathrm{~h}$ at room temperature in the dark. Then, $100 \mu \mathrm{l}$ of $0.8 \mathrm{M}$ Tris- $\mathrm{HCl}(\mathrm{pH} 8.0)$ was added, to reach a final Tris- $\mathrm{HCl}$ concentration of $20 \mathrm{mM}$, and dialyzed against phosphate-buffered saline (PBS). The activity of $20 \mu \mathrm{g} / \mathrm{ml}$ of PgAFP labeled with FITC was checked in a growth inhibition assay as described above. Then, A. flavus was grown in PDB for 6 and $24 \mathrm{~h}$ at $25^{\circ} \mathrm{C}$ in presence of $20 \mu \mathrm{g} / \mathrm{ml}$ of PgAFP labeled with FITC. Hyphae were washed twice with PBS and visualized by fluorescence microscopy with excitation wavelength of $482 / 35 \mathrm{~nm}$. As controls, two additional tests were run: the PgAFP-resistant $P$. chrysogenum grown with PgAFP labeled with FITC and $A$. flavus grown with FITC-PgAFP previously treated at $121^{\circ} \mathrm{C}$ for $15 \mathrm{~min}$.

\section{ROS detection}

Induction of ROS production by PgAFP was evaluated using $2^{\prime}, 7^{\prime}$-dichlorofluorescein diacetate (Sigma-Aldrich, St. Louis, MO, USA) as described previously (Kaiserer et al. 2003) with some modifications. A. flavus was grown as described in FUN-1 assay section; hyphae were incubated for $2 \mathrm{~h}$ at $25{ }^{\circ} \mathrm{C}$ with $20 \mu \mathrm{M}$ fluorescent dye and observed by fluorescence microscopy with excitation wavelength of $482 / 35 \mathrm{~nm}$. Additionally, the resistant $P$. chrysogenum was used as negative control.

\section{Acridine orange/ethidium bromide double staining}

A. flavus incubated at $25^{\circ} \mathrm{C}$ for $24 \mathrm{~h}$ in either presence (20 and $75 \mu \mathrm{g} / \mathrm{ml}$ ) or absence of PgAFP was stained with $4 \mu \mathrm{g} / \mathrm{ml}$ of acridine orange/ethidium bromide (AO/EB; Sigma-Aldrich, St. Louis, MO, USA), incubated $30 \mathrm{~min}$, and washed twice to be observed by fluorescence microscopy (excitation wavelengths, 482/35 and 562/40 nm). P. chrysogenum grown with $75 \mu \mathrm{g} / \mathrm{ml}$ PgAFP was also stained as negative control.

\section{Apoptosis induction by PgAFP}

Apoptosis Detection Kit (Sigma-Aldrich, St. Louis, MO, USA) composed by annexin V-fluorescein isothiocyanate/ propidium iodide (AnV-FITC/PI) was carried out according to manufacturers' instruction to distinguish between necrotic, late apoptotic, and viable cells in cultures of A. flavus incubated at $25^{\circ} \mathrm{C}$ for 12 and $24 \mathrm{~h}$ in either presence $(20 \mu \mathrm{g} / \mathrm{ml})$ or absence of PgAFP. Likewise, P. chrysogenum was assayed as negative control.

\section{Statistical analysis}

Statistical analyses were performed with IBM SPSS v.22 (www-03.ibm.com/software/products/es/spss-stats-standard). Growth inhibition and membrane permeability data were 
tested for normality (Kolmogorov-Smirnov with Lilliefors correction) and homoscedasticity (Levene's test). Given that these data were non-normally distributed, mean values were compared using non-parametric Kruskal-Wallis test. To compare treatments in pairs, Mann-Whitney $U$ test was applied $(p<0.05)$.

\section{Results}

\section{Effect of PgAFP on A. flavus growth}

The study of the inhibitory effect revealed that concentrations of PgAFP from $9.38 \mu \mathrm{g} / \mathrm{ml}$ reduced A. flavus growth at $48 \mathrm{~h}$ $(p<0.05)$ in static culture, with differences increasing up to the end of the incubation time (Fig. 1). According to optical density reductions, over $50 \%$ growth inhibition was reached with $18.75 \mu \mathrm{g} / \mathrm{ml}$ PgAFP or above, at $96 \mathrm{~h}$. However, no statistically significant difference was found among A. flavus inhibition with PgAFP concentrations over $9.38 \mu \mathrm{g} / \mathrm{ml}$. No growth difference was observed at 24-h incubation among samples with the various concentrations assayed. All samples are in the exponential growth phase at $48 \mathrm{~h}$ (Fig. 1), revealing that the lag phase was very similar in all conditions tested, even the non-treated samples. Similarly, all cultures were at the exponential growth phase at 96-h incubation time.

\section{Effect on protein profile}

A comparative proteomic analysis of $A$. flavus in either presence or absence of PgAFP was carried out to study the metabolic pathways altered by this antifungal protein. A relatively low concentration of PgAFP was used in this assay $(10 \mu \mathrm{g} / \mathrm{ml})$ so as to reach a balance between fungistatic effect and sufficient growth in $24 \mathrm{~h}$ under continuous shaking. All samples showed a sufficient growth at harvesting time. Both untreated and PgAFP-treated cultures under continuous shaking were in the exponential growth phase from 24 to $48 \mathrm{~h}$ according to mycelium dry weight (data not shown). From gel-based proteomics, only 26 spots showed a fold change $\geq 1.5$ between the relative abundance of PgAFP-treated and untreated samples and were identified $(p<0.05)$. However, it appeared that these 26 spots belong to 23 unique proteins. Three spots were isoforms of pyruvate carboxylase, and the putative Hsp70 chaperone HscA was identified from two spots (Table 1), each with different molecular masses and charges possibly due to breakdown and side-chain deamination. In PgAFP-treated samples, the relative abundance was 1.6-3.5-fold higher for 13 spots, whereas 13 were 1.6-3.6-fold lower (Table S2 in the Supplementary Material).

The label-free quantitative analysis led to the identification of 1733 unique proteins (identification by at least 2 peptides per protein), and with each validated protein detected in a minimum of $2 / 3$ biological replicates from at least one treatment group. Of these proteins, 367 were identified whose relative abundance suffered some change, either quantitative $(n=231)$ or qualitative $(n=136)$ (Table $\mathrm{S} 1$ in the Supplementary Material), using methods described above. All 23 proteins showing significant changes in 2D gels were also identified by label-free quantitative analysis. From these, six proteins showed a similar fold change in both methods. The remaining 17 reached at least a 1.5 -fold change in gelbased analysis but did not reach the twofold change threshold in label-free proteomic analysis. The presence of isoforms could explain these differences. PgAFP-treated samples contained 104 proteins with higher abundance, from 2- to 288 -fold $(p<0.05)$, and 67 proteins were exclusively detected following PgAFP exposure. In addition, untreated samples showed 127 proteins in higher abundance, between 2- and 202 -fold $(p<0.05)$, and 69 proteins were exclusively detected in these samples. Scatterplot analysis of data from the labelfree study revealed strong correlation within the biological replicates from each respective treatment group (Pearson correlation values $>0.95$ ), confirming high
Fig. 1 Effect of different concentrations of PgAFP on $A$. flavus growth for $96 \mathrm{~h}$

\section{Aspergillus flavus}

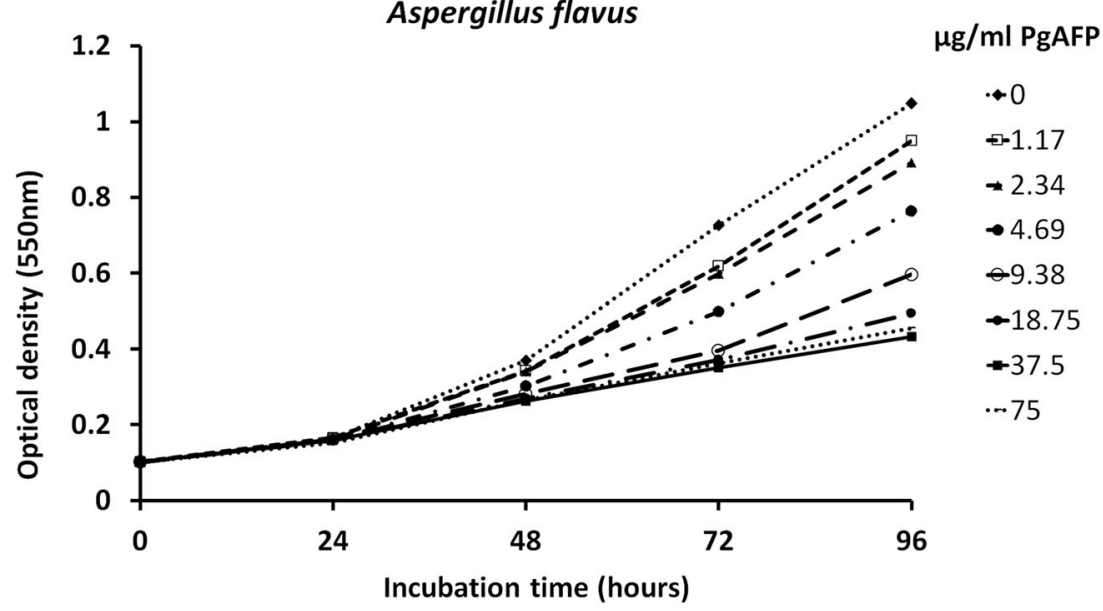


Table 1 Selected proteins whose relative abundance was affected by PgAFP in A. flavus reaching over 1.5-fold change in 2D-PAGE or 2.0-fold change in label-free proteomics (LFP) analysis. Data are given according to four groups of metabolic pathways

\begin{tabular}{|c|c|c|}
\hline Proteins involved in pathways & Detection method & Fold change \\
\hline \multicolumn{3}{|l|}{ Energy metabolism related to glycolysis and gluconeogenesis } \\
\hline Pyruvate decarboxylase & 2D-PAGE and LFP & +1.6 and $<2$ \\
\hline Phosphoglucomutase & 2D-PAGE and LFP & +1.6 and $<2$ \\
\hline Pyruvate carboxylase (three isoforms) & 2D-PAGE and LFP & $-1.9 /-1.7 /-1.7$, and -2.1 \\
\hline Acetate-CoA ligase & 2D-PAGE and LFP & -1.7 and -2.7 \\
\hline Aldose 1-epimerase & LFP & $\mathrm{NT}^{\mathrm{b}}$ \\
\hline Phosphoenolpyruvate carboxykinase & LFP & -2.67 \\
\hline Aldehyde dehydrogenase & LFP & -2.45 \\
\hline Phosphofructokinase & LFP & -3.34 \\
\hline Acetyl-CoA carboxylase ${ }^{\mathrm{a}}$ & LFP & -2.34 \\
\hline Malate synthase & LFP & -8.55 \\
\hline \multicolumn{3}{|l|}{ Stress response and glutathione metabolism } \\
\hline Molecular chaperone and allergen Mod-E/Hsp90/Hsp1 & 2D-PAGE and LFP & +3.3 and $<2$ \\
\hline Hsp70 chaperone (two isoforms) & 2D-PAGE and LFP & $+1.7 /+1.7$ and $<2$ \\
\hline Chaperonin & LFP & +5.63 \\
\hline Cys-Gly metallodipeptidase Dug1 & 2D-PAGE and LFP & +1.7 and $<2$ \\
\hline Glutathione synthetase & 2D-PAGE and LFP & +1.6 and $<2$ \\
\hline Elongation factor 1 gamma & LFP & NT \\
\hline Gamma-glutamyltranspeptidase & LFP & -2.63 \\
\hline Glutathione S-transferase $^{\mathrm{a}}$ & LFP & -2.42 \\
\hline $\mathrm{G}$ protein complex beta subunit $\mathrm{CpcB}$ & LFP & -2.85 \\
\hline \multicolumn{3}{|l|}{ Cell wall integrity, chitin biosynthesis, and permeability } \\
\hline Actin Act1 & 2D-PAGE and LFP & -2.2 and -5.16 \\
\hline Septin AspA & 2D-PAGE and LFP & -2 and -2.15 \\
\hline Probable beta-glucosidase btgE & LFP & +3.64 \\
\hline Cell wall glucanase & LFP & $\mathrm{T}^{\mathrm{c}}$ \\
\hline Mannose-1-phosphate guanylyltransferase & LFP & -11.9 \\
\hline Glucosamine-fructose-6-phosphate aminotransferase & LFP & -5.64 \\
\hline Alpha, alpha-trehalose-phosphate synthase subunit putative & LFP & -4.21 \\
\hline Septin & LFP & -3.02 \\
\hline Rho GTPase Rhol & LFP & -2.68 \\
\hline GDP-mannose pyrophosphorylase A & LFP & -2.42 \\
\hline Septin AspB & LFP & -2.06 \\
\hline \multicolumn{3}{|l|}{ Aflatoxin biosynthesis } \\
\hline Acetyl-CoA carboxylase $^{\mathrm{a}}$ & LFP & -2.34 \\
\hline AflK/vbs/VERB synthase & LFP & NT \\
\hline AflM/ver-1/dehydrogenase/ketoreductase & LFP & NT \\
\hline Glutathione S-transferase $^{\mathrm{a}}$ & LFP & -2.42 \\
\hline$O$-Methyltransferase, putative & LFP & -30.18 \\
\hline
\end{tabular}

${ }^{a}$ Protein involved in more than one pathway

${ }^{\mathrm{b}}$ NT: Protein only detected in non-treated samples

${ }^{\mathrm{c}} \mathrm{T}$ : Protein only detected in treated samples

reproducibility from the biological replicates (Fig. S1, Table S3 in the Supplementary Material). Among the characterized proteins, the highest increases in PgAFPtreated samples were detected for ribosomal $40 \mathrm{~S}$ and
$60 \mathrm{~S}$ proteins, as well as other putative proteins such as translation initiation factors, small nuclear ribonucleoproteins, RNA binding, and splicing proteins, many being uniquely detected in PgAFP-treated samples. 
According to KEGG, in addition to ribosomal, spliceosomal, RNA transport, and degradation proteins, hyphae biogenesis proteins also increased upon PgAFP exposure. Interestingly, PgAFP exposure attenuated abundance of proteins related to a number of cellular systems, such as glycolysis and gluconeogenesis, stress response, cell wall integrity, and aflatoxin biosynthesis (Table 1). Two of these proteins play crucial roles in signaling the cell response to external factors, including antifungal compounds in A. nidulans (Coca et al. 2000) and in Saccharomyces cerevisiae (Fuchs and Mylonakis 2009): the G protein complex $\beta$ subunit $\mathrm{CpcB}$ and Rho-GTPase Rho1, respectively. The aflK/vbs/VERB synthase and AflM/ver-1/dehydrogenase/ketoreductase, both involved in the aflatoxin pathway (Yu et al. 2004) and identified in all control samples, were no longer detectable following PgAFP treatment. Additionally, acetyl-CoA carboxylase, $O$-methyltransferase, and glutathione S-transferase also related to aflatoxin production (Allameh et al. 2002) were found in lower relative amounts in PgAFP-treated samples.

\section{Effect on metabolic activity}

To obtain evidences of the metabolic alterations suggested by the comparative proteomics, the metabolic activity was checked with FUN-1 staining. The reduction of metabolic activity was assessed by the yellow-green fluorescence of treated sensitive hyphae, in contrast to the presence of intravacuolar red spots in unaffected controls, as described by Kaiserer et al. (2003). A dramatic difference between PgAFP-treated and untreated A. flavus was found. PgAFPtreated samples showed green fluorescence but almost no red intravacuolar fluorescence (Fig. 2), meaning metabolically inactive hyphae. In contrast, untreated A. flavus (Fig. 2) and PgAFP-treated $P$. chrysogenum (data not shown) exhibited a high content of red intravacuolar fluorescence due to unaltered metabolic activity.

\section{Morphology}

To study morphological changes, septa distribution, nuclei localization, and chitin deposition, in addition to the standard concentration of $20 \mu \mathrm{g} / \mathrm{ml}$ used in other assays, an additional test was run with $75 \mu \mathrm{g} / \mathrm{ml}$ PgAFP to obtain unambiguous results. Among the different tests used to visualize morphological changes induced by PgAFP, no changes in germination or branching were detected by bright light microscopy. Nuclei localization and distribution by fluorescence microscopy with Hoechst 33258 stain showed no abnormal distribution compared to control samples. Septa distribution, checked with fluorescent brightener 28, showed no differences between PgAFP-treated and untreated samples after 24-h incubation (data not shown). Figure 3 shows the fluorescence intensity of the stained PgAFP-treated and untreated hyphae at an early incubation time (12 h). Both micrographs were taken with the same exposure to compare the chitin present. The fluorescence of PgAFP-treated hyphae appeared to be lower than that of untreated samples (Fig. 3).

\section{Effect on membrane permeability and PgAFP localization}

Given that the activity of most studied small, highly basic, and cysteine-rich antifungal proteins from molds has been related to interactions with the outer layer of sensitive molds, the level of cell membrane compromise was tested with the SYTOX Green uptake test. Mean $( \pm \mathrm{SD})$ fluorescence values at 210 min after SYTOX Green addition to A. flavus increased up to $23,342( \pm 2992)$ arbitrary units as PgAFP concentration increased from 0 to $4.69 \mu \mathrm{g} / \mathrm{ml}$ but progressively decreased down to $11,550( \pm 2155)$ arbitrary units from 9.38 to $75 \mu \mathrm{g} / \mathrm{ml}$ (Fig. 4). Nonetheless, the fluorescence in all PgAFP-treated $A$. flavus was at least $27 \%(p<0.05)$ higher than that in the untreated control, except for the lowest PgAFP concentration $(1.2 \mu \mathrm{g} / \mathrm{ml})$ at $10 \mathrm{~min}$ after SYTOX Green addition. In contrast, the fluorescence after SYTOX Green addition to the PgAFP producer $P$. chrysogenum did not exceed $25 \%$ over that in non-treated samples at any PgAFP concentration assayed (data not shown). To determine the localization of PgAFP, A. flavus was treated with FITC-labeled PgAFP. To check whether FITC labeling decreased the antifungal activity of PgAFP, an antifungal assay was run. No differences $(p>0.05)$ were found between cultures treated with labeled
Fig. 2 Metabolic activity of $A$. flavus tested with FUN-1 staining. Non-treated hyphae (left) showed intravacuolar activity as red spots; hyphae treated with $20 \mu \mathrm{g} / \mathrm{ml}$ PgAFP for $24 \mathrm{~h}($ right $)$ showed scarcely red spots
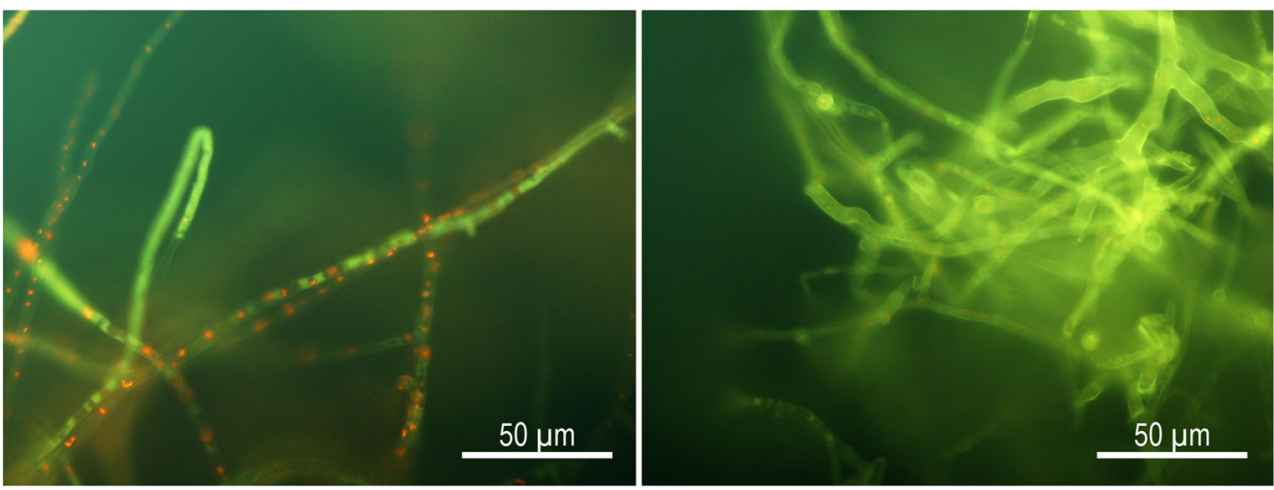
Fig. 3 Chitin distribution on $A$ flavus stained with fluorescent brightener 28. Left: non-treated hyphae; right: hyphae treated with $75 \mu \mathrm{g} / \mathrm{ml}$ PgAFP for $12 \mathrm{~h}$

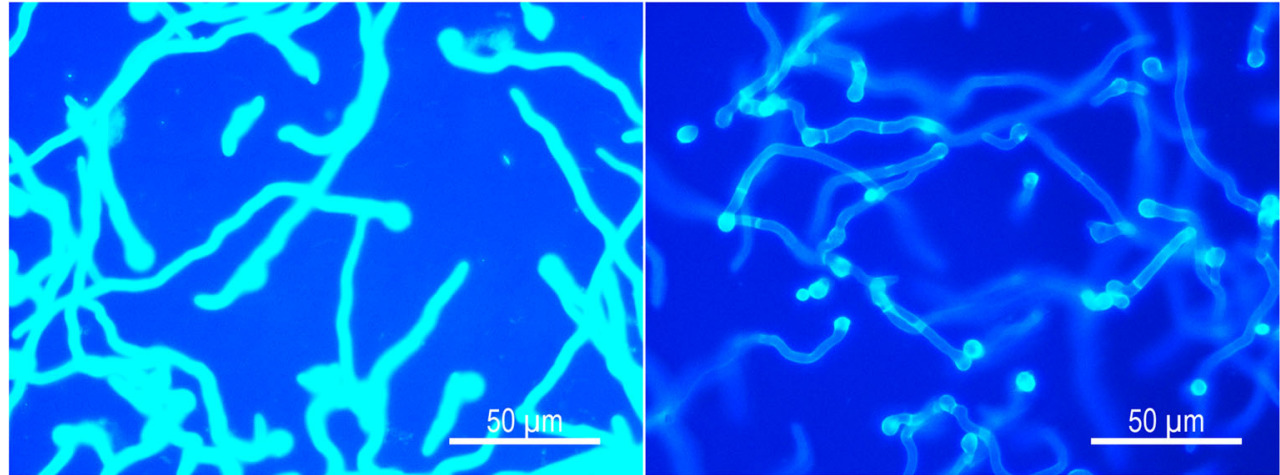

and those treated with non-labeled PgAFP (data not shown). Localization of PgAFP by fluorescence microscopy after treatment of $A$. flavus with FITC-labeled PgAFP revealed green fluorescence only at the outer layer at 6-h incubation time but both inside and bound to the outer layer on treated hyphae at $24 \mathrm{~h}$ (Fig. 5). In contrast, FITC-labeled PgAFP neither bound nor penetrated in the resistant $P$. chrysogenum (Fig. 5). Additionally, the heat-denatured FITC-PgAFP was not bound to or inside the hyphae (data not shown).

\section{Effect on oxidative status and viability}

To discern whether the changes in the proteins related to oxidative stress were provoked by a high ROS level, staining with 2',7'-dichlorofluorescein diacetate was carried out, where a green fluorescence reveals the presence of intracellular ROS as described by Kaiserer et al. (2003). The most intense oxidative activity was observed in PgAFP-treated A. flavus, whereas non-treated hyphae only showed a very weak halo (Fig. 6). Given that ROS may induce severe cell damage, the viability of PgAFP-treated $A$. flavus was evaluated with the $\mathrm{AO} / \mathrm{EB}$ double staining to check for necrosis and also with AnV-FITC/PI staining to detect apoptotic processes. With $\mathrm{AO} / \mathrm{EB}$ double staining, an additional treatment with

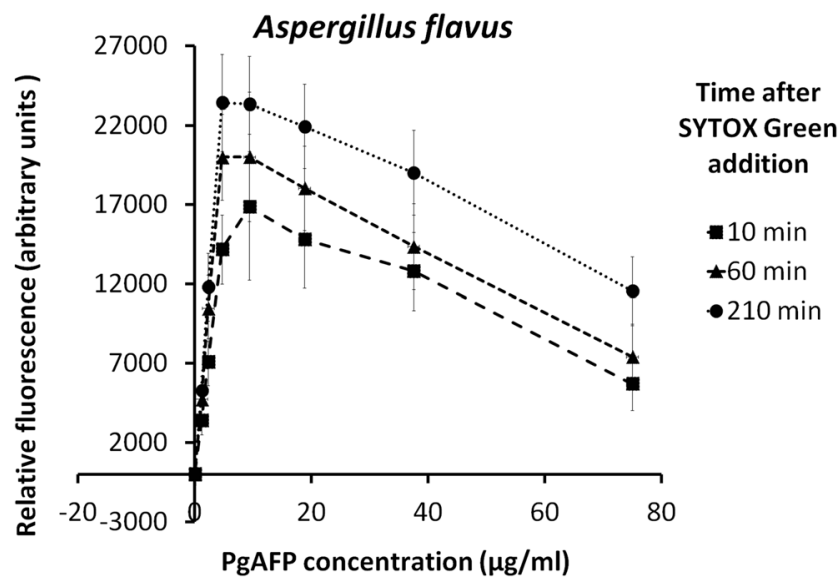

Fig. 4 SYTOX Green uptake with different concentrations of PgAFP on A. flavus at $24 \mathrm{~h}$ (bars represent standard deviation of the mean)
$75 \mu \mathrm{g} / \mathrm{ml}$ PgAFP was also tested to obtain unambiguous results. A massive loss in viability was observed at $24 \mathrm{~h}$ in hyphae treated with $75 \mu \mathrm{g} / \mathrm{ml}$ (Fig. 7). Untreated hyphae displayed a green color, meaning that they remained viable (Byczkowska et al. 2012). The intense orange staining revealed a high penetration of EB in the PgAFP-treated hyphae through a highly compromised cell membrane. Untreated samples were not stained by AnV-FITC/PI, indicating that they were viable. (Fig. 8a). The orange staining of DNA in PgAFP-treated samples by PI indicated cell membrane damage associated with a necrotic stage (Fig. 7b). The generalized necrosis observed can be due to the fact that an advanced stage of cell death was reached at $24 \mathrm{~h}$ in nearly all PgAFP-treated hyphae. AnV-FITC staining was used to detect phosphatidylserine translocation to the external side of the plasma membrane due to apoptosis. However, the green fluorescence observed in PgAFP-treated hyphae at $24 \mathrm{~h}$ cannot be attributed to apoptosis, because the compromised cell membrane would allow AnV-FITC to enter and bind phosphatidylserine at the inner layer of plasma membrane. To detect potential apoptotic signals previous to the necrotic stage, an additional AnV-FITC/PI staining was carried out at $12 \mathrm{~h}$. The evaluation of phosphatidylserine translocation at this earlier stage revealed some hyphae showing solely green color due to apoptosis (Fig. 8c). All these ROS and viability assays for PgAFP-treated and untreated $P$. chrysogenum gave very similar results to those obtained for untreated A. flavus (data not shown).

\section{Discussion}

PgAFP reduced $A$. flavus growth following a dose-dependent pattern (Fig. 1). The inhibition rate reached with PgAFP at $37.5 \mu \mathrm{g} / \mathrm{ml}$ was $59 \%$, calculated from the percent difference in $\mathrm{OD}_{550}$ compared to untreated controls. Similar results were obtained with PAF against $A$. flavus, reaching a $69 \%$ growth reduction with $50 \mu \mathrm{g} / \mathrm{ml}$ (Kaiserer et al. 2003) and $50 \%$ growth reduction with $3 \mu \mathrm{M}(18.9 \mu \mathrm{g} / \mathrm{ml})$ (Marx et al. 2008). The first $24 \mathrm{~h}$ of incubation did not show any statistical 
Fig. 5 PgAFP localization in $A$. flavus and $P$. chrysogenum treated with $20 \mu \mathrm{g} / \mathrm{ml}$ FITC-labeled PgAFP. (a) A. flavus. Left: At 6-h incubation, PgAFP was found solely bound to the outer layer. Right: At 24-h incubation, PgAFP was detected bound to the outer layer and occasionally inside the cell (arrows). (b) P. chrysogenum. Left: At 24-h incubation, PgAFP was neither bound nor inside the hyphae. Right: Bright field observation of the same preparation showing profuse growth

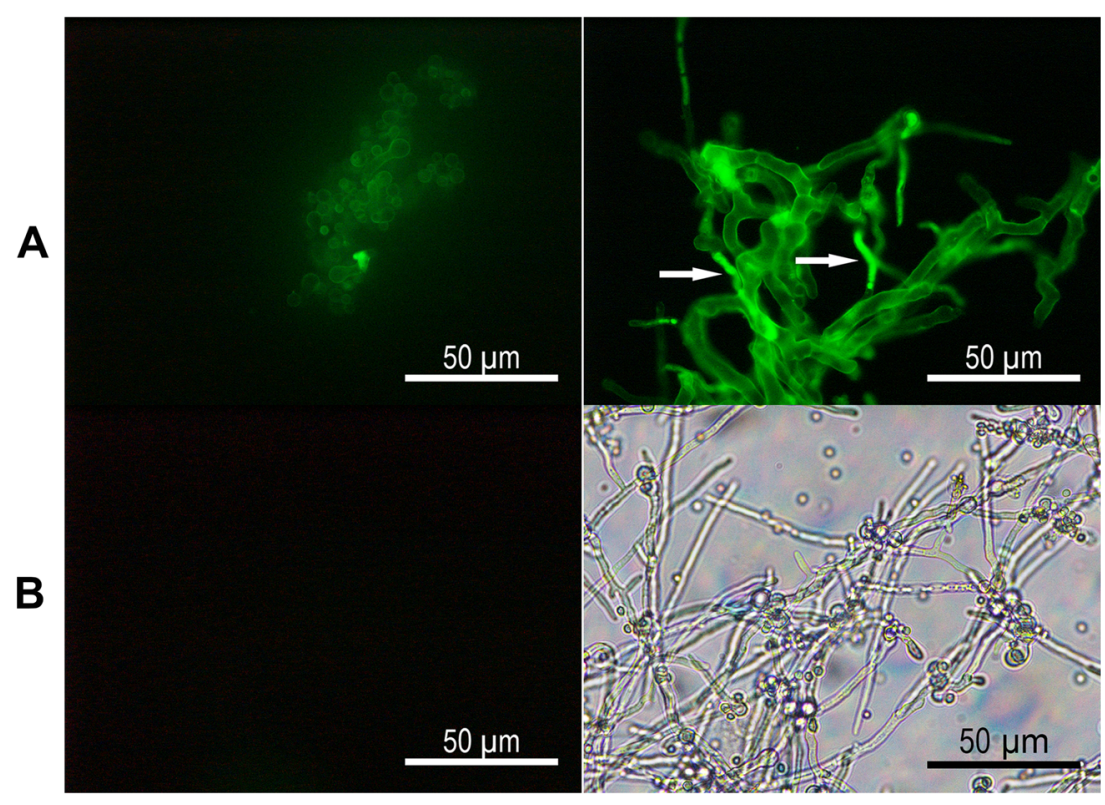

differences in growth, due to the limited fungal growth at this time point under the conditions assayed. Even the highest PgAFP concentrations tested $(75 \mu \mathrm{g} / \mathrm{ml})$ did not lead to total inhibition of A. flavus, which implies only a fungistatic effect.

Using gel-based proteomics, a total of 23 unique proteins, identified from 26 independent spots (Table S2 in the Supplementary Material), were observed to undergo a significant change in abundance in A. flavus in response to PgAFP. A concurrent analysis using label-free quantitative mass spectrometry-based proteomics revealed a more in-depth view of the response to PgAFP, with 231 quantitative changes in protein abundance and 136 qualitative differences following treatment. The dynamic range of gel-based proteomics, using colloidal Coomassie Blue stain as a visualization technique, is limited to approximately 1 order of magnitude (Gauci et al. 2011). As a result, the proportion of the proteome available for analysis using gel-based methods is constrained by relative protein abundance. In comparison, label-free proteomics is capable of measuring protein abundances across larger dynamic ranges, with proteins identified across 4 orders of magnitude in this study (Table S1 in the Supplementary Material).
In order to reduce the possibility of inclusion of false positives in this larger data set, a fold change cutoff of 2 was employed. In addition, differing capacities for resolution of proteins with extremes in $\mathrm{p} I$, molecular mass, and hydrophobicity (Owens et al. 2014) can contribute to the lower number of abundance changes detected using gel-based proteomics. Furthermore, the limitations of the label-free proteomic technique with regard to capability to analyze isoforms could explain the different quantification of proteins when isoforms were involved. For example, multiple Hsp70 isoforms have been described in the eukaryotic cytosol (Kabani and Martineau 2008). Although an increase of Hsp70 chaperone (HscA) was detected in gel-based proteomic analysis, no significant change in abundance was detected for Hsp70 chaperone (HscA) by label-free analysis. This may indicate that the abundance difference detected by 2D-PAGE for this protein may be the result of a post-translational event, which altered the ratio of the different isoforms instead of the total HscA protein abundance.

A substantial number of ribosomal proteins were detected with increased abundance in response to PgAFP, in addition to
Fig. 6 ROS induction by PgAFP on $A$. flavus detected by $2^{\prime}, 7^{\prime}$ dichlorofluorescein diacetate staining. Non-treated A. flavus (left) did not show green fluorescence inside of the cells; hyphae treated with $20 \mu \mathrm{g} / \mathrm{ml}$ PgAFP for $24 \mathrm{~h}($ right $)$ showed strong green fluorescence due to intracellular ROS
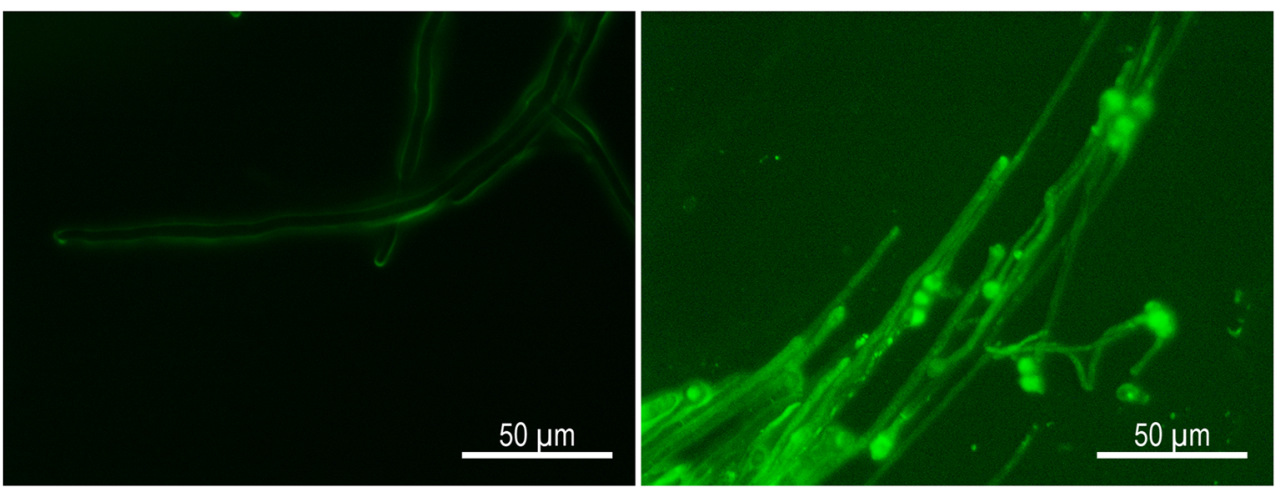
Fig. 7 Effect of PgAFP on hyphae viability evaluated with vital acridine orange $(\mathrm{AO}) /$ ethidium bromide (EB) staining. a Non-treated hyphae of $A$. flavus showing an intense green color (AO). b Seventy-five microgram per milliliter PgAFP-treated hyphae showing an intense red color (EB) due to compromised cell membrane

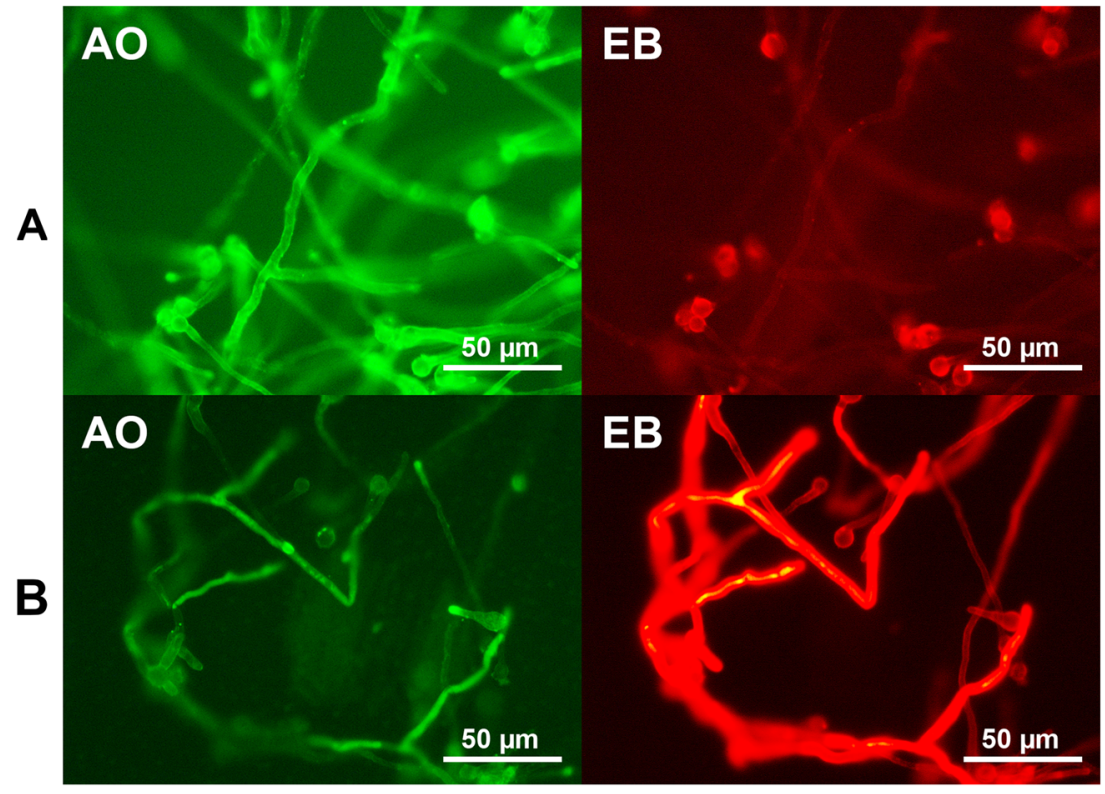

proteins involved in RNA transport and degradation, and the spliceosome. Ribogenesis and translation are energy-hungry processes, which are normally associated with germination or cell growth (Lamarre et al. 2008). This observed increase in the translational machinery, coupled with the decrease in metabolism-associated mechanisms, could lead to depletion of the cell energy reserves and result in the fungistatic effect of PgAFP on A. flavus. The main pathways identified with

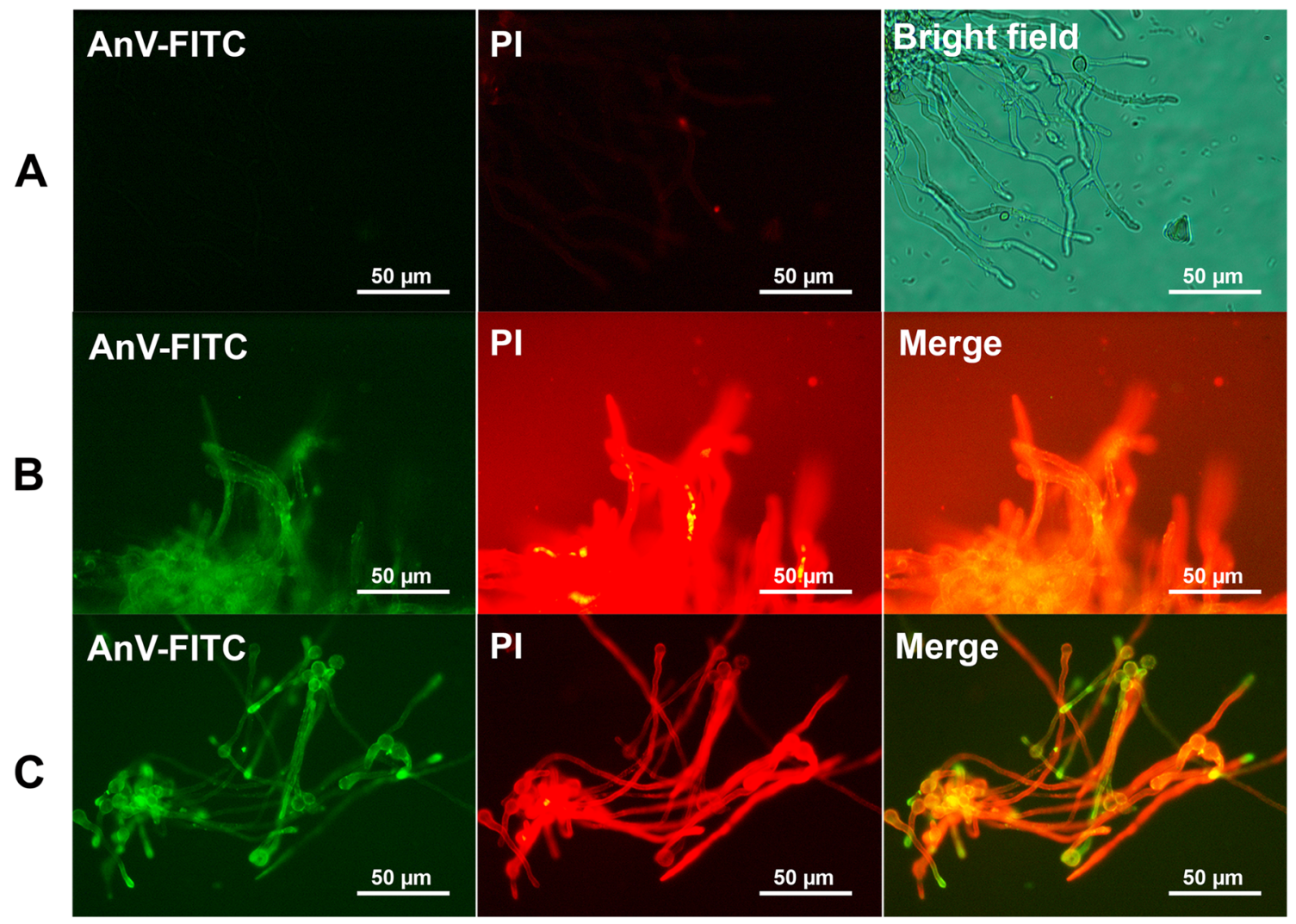

Fig. 8 Effect of PgAFP on A. flavus hyphae viability evaluated with apoptosis detection kit. a Non-treated hyphae showing no apoptosis or necrosis signal at $24 \mathrm{~h}$. b Hyphae treated with $20 \mu \mathrm{g} / \mathrm{ml}$ PgAFP for $24 \mathrm{~h}$ showing an intense red color (PI) due to necrosis that leads to mainly orange color in the merged picture. $\mathbf{c}$ Hyphae treated with PgAFP for $12 \mathrm{~h}$ revealing apoptotic signals by the green fluorescence (AnV-FITC) that leads to green hyphae in the merged picture 
proteins showing changes in relative abundance due to PgAFP are involved in energy metabolism, cell stress response, hyphae biogenesis, and aflatoxin biosynthesis (Table 1). The proteins related to energy metabolism showing a lower abundance in PgAFP-treated samples were pyruvate carboxylase, phosphofructokinase, aldose 1-epimerase, phosphoenolpyruvate carboxykinase, aldehyde dehydrogenase, malate synthase, acetate-CoA ligase, and acetyl-CoA carboxylase. These enzymes play essential roles in glycolysis and gluconeogenesis pathways, and the lower quantity would depress the metabolic activity. This effect is supported by the results obtained from the FUN-1 staining (Fig. 2) where PgAFPtreated samples showed reduced metabolic hyphae activity. A reduced metabolic activity has been also described with FUN-1 staining for PAF in A. niger (Kaiserer et al. 2003).

A. flavus is not completely killed, even at the highest PgAFP concentration assayed. This fact suggests that $A$. flavus invests in alternative ways to obtain the necessary energy to grow. This seems to be achieved through anaerobic pathways led by pyruvate decarboxylase, whose relative quantity was higher in PgAFP-treated samples. Pyruvate decarboxylase is involved in alcoholic fermentation under anaerobic stress (Lockington et al. 1997). Thus, the pyruvate presumptively accumulated due to the lower pyruvate carboxylase presence with PgAFP would be used as substrate by pyruvate decarboxylase. However, this pathway would not provide enough energy to keep a normal growth rate. The lower abundance of proteins involved in hyphae structure, such as septins and actin, may provoke morphological changes, such as those caused by AFP1 from Streptomyces tendae and PAF in sensitive molds (Bormann et al. 1999; Kaiserer et al. 2003). Septin AspA, AspB, and AspC are necessary for normal development and morphogenesis (Lindsey et al. 2010; Hernández-Rodríguez et al. 2012). Actin is necessary for cell wall and membrane extension (Fischer et al. 2008). The lower relative abundance of septins and actins detected in PgAFPtreated A. flavus suggests morphological changes, as it has been shown for Aspergillus spp. treated with PAF due to actin gene repression (Kaiserer et al. 2003; Binder et al. 2010). Despite the altered quantity of proteins, no morphological change was visualized in hyphae and nuclei distribution in PgAFP-treated A. flavus.

Similarly to PgAFP, AFP from A. giganteus did not cause morphological changes in sensitive molds (Theis et al. 2003) but binds to regenerated chitin (Liu et al. 2002) and specifically inhibits chitin synthesis, causing cell wall stress and disturbing cell integrity (Hagen et al. 2007). However, AFP1 also binds to chitin but causes severe alteration in cell morphogenesis (Bormann et al. 1999). In fact, proteins participating in chitin pathway were found in lower relative amount in PgAFP-treated $A$. flavus, such as the putative $\alpha$-trehalosephosphate synthase subunit $\alpha$, glucosamine-fructose-6phosphate aminotransferase, mannose-1-phosphate guanylyltransferase, and GDP-mannose pyrophosphorylase A. Furthermore, a cell wall glucanase, whose main function involves degrading chitin, was found exclusively in PgAFPtreated samples. These changes in the relative abundance of chitin-related proteins could explain a smaller deposition of chitin on cell wall of $A$. flavus at 12-h incubation time as suggested by the fluorescent brightener 28 staining (Fig. 3). A lower quantity of chitin may be related to the mode and the site of action of PgAFP, as it has been reported for AFP (Hagen et al. 2007). Regarding cell wall glucanase, its detection only in PgAFP-treated samples can be a consequence to counteract PgAFP binding to chitin. PAF exposure resulted in a deregulation of the chitin deposition at hyphal tips (Binder et al. 2010). Therefore, the smaller amount of septins, actin, and chitin, seems not to be enough to provoke morphological changes in hyphae but could affect normal growth and cell wall integrity. In addition, eleven proteins related to cell wall integrity showed lower relative abundance in PgAFP-treated samples (Table 1). Rhol GTPase is considered the master regulator of cell wall integrity signaling and it is involved in actin organization in S. cerevisiae (Levin 2005). A. nidulans cells treated with PAF fail to activate MpkA, a target of GTPase RhoA signaling, disrupting basal resistance towards antifungal activity (Binder et al. 2010). In addition, $A$. nidulans lacking RhoA display pronounced hypersensitivity to cell wall-interfering drugs (Guest et al. 2004). GDPmannose pyrophosphorylase has been described as essential for cell wall integrity, morphogenesis, and viability of Aspergillus fumigatus (Jiang et al. 2008), and it also seems to be related to regulation of the selective permeability (Agaphonov et al. 2001).

AFP specifically inhibits in situ activity of chitin synthases classes III and V in sensitive fungi, which would disturb cell integrity, but it strongly induced cell wall integrity pathway in A. niger as a compensatory response (Hagen et al. 2007). Similarly, reinforcement of chitin synthesis has been described as a distinctive feature of AFP-moderate sensitive and AFPresistant fungi, whereas it is not realized in AFP-sensitive fungi (Ouedraogo et al. 2011). This elevation of chitin levels has been interpreted as the necessary response to survive an AFP attack. Therefore, it seems that the mode of action of AFP is based on cell wall alterations. However, as it has been mentioned above, PgAFP repressed the cell wall integrity pathway and chitin biosynthesis in treated A. flavus. This would increase membrane exposure to PgAFP. Actually, PgAFP increased permeability at all concentrations tested (Fig. 4). Notwithstanding this, the highest SYTOX Green uptake was observed at low PgAFP concentrations ( $4.69 \mu \mathrm{g} / \mathrm{ml})$. A similar fact has been described for plant defensin DmAMP1, whose dose-response curves for SYTOX Green uptake declined at doses above those providing maximum effect (Thevissen et al. 1999). In contrast, the inhibition assay exhibited a dose-response effect of PgAFP in the whole range of 
concentrations tested. The lower SYTOX Green uptake at the highest PgAFP concentrations could be related to the apparent dependency of membrane polarization, as it has been shown for various antifungal proteins that depolarize the membrane (Thevissen et al. 1996).

Treatment of $A$. flavus with PgAFP-FITC revealed that PgAFP is bound to outer layer and also is present in the cytoplasm. Other antifungal proteins, such as AFP, bind the outer layer of sensitive fungi and also can be found intracellularly in collapsed and dead cells (Theis 2003, 2005). The antifungal activity of AFP is related to its ability to interact with anionic phospholipids (Lacadena et al. 1998). Such interaction would promote the insertion of the antifungal protein into the plasma membrane of the sensitive fungi (Marx et al. 2008). In contrast, PAF is actively internalized only in sensitive fungi (Oberparleiter et al. 2003; Batta et al. 2009). Thus, it seems that PgAFP induces the aforementioned changes in membrane permeability after binding to the outer layer. Given that the results obtained at $24 \mathrm{~h}$ did not allow the confirmation that PgAFP is inside non-compromised cells, PgAFP internalization cannot be ruled out.

Additionally, the above changes in energy metabolism and cell wall integrity are aggravated by cell damage due to ROS generation. Among other negative effects on lipids and nucleic acids, ROS also cause protein aggregation and amyloid formation (Squier 2001), compromising cell viability (Cabiscol et al. 2000). Heat shock proteins were found in higher relative abundance in PgAFP-treated samples. These proteins are involved in stress, preventing aggregation and assisting refolding of misfolded proteins (Bukau and Horwich 1998). The observed higher abundance of heat shock proteins could represent a defense mechanism to neutralize ROS effects on proteins.

Increased abundance of two proteins involved in the glutathione pathway was also found: glutathione synthetase (GS) and Cys-Gly metallodipeptidase Dug1. Glutathione (GSH) has pivotal roles in protection against oxidative stress provoked by exposure of cells to ROS (Penninckx 2002). Therefore, GSH overproduction due to the increased GS could counteract ROS present in the cell, as it has been described for PAF (Leiter et al. 2005). A higher amount of ROS was confirmed by fluorescence staining in PgAFP-treated samples (Fig. 6). In addition, $\gamma$-glutamyltranspeptidase $(\gamma \mathrm{GT})$ was found in lower amount in PgAFP-treated A. flavus. This enzyme is involved in glutathione catabolism, releasing the CysGly dipeptide (Kaur et al. 2009). Furthermore, the Cys-Gly metallodipeptidase Dug1 degrades the Cys-Gly dipeptide, recovering glycine and cysteine for GSH synthesis by GS. The higher relative abundance of Cys-Gly metallodipeptidase Dug1 observed in PgAFP-treated A. flavus would help counteract high ROS levels. Thus, it seems that $A$. flavus also uses GSH metabolism to counteract PgAFP action due to ROS production. However, as discussed later, $G$ protein subunit $\beta$
CpcB may also play an essential role modulating the intracellular levels of glutathione and ROS.

Despite the production of heat shock proteins and GSH to combat ROS, the defense mechanism of $A$. flavus does not seem to be effective against PgAFP. The observed increase of ROS in PgAFP-treated samples could explain A. flavus inhibition. These substances can act as primary triggers of apoptosis (Slater et al. 1995). The loss of cell membrane integrity revealed by $\mathrm{AO} / \mathrm{EB}$ double staining and the annexin $\mathrm{V}$ FITC and PI staining (Figs. 7 and 8) is a necrotic signal derived from the observed apoptotic process, likely triggered by ROS (Hamann et al. 2008). Thus, the A. flavus response to counteract ROS seems insufficient to prevent the necrotic process. PAF needs active $G$ protein signaling to inhibit the growth of the sensitive organism (Leiter et al. 2005). A lower relative amount of $\mathrm{G}$ protein complex $\beta$ subunit $\mathrm{CpcB}$ was found in PgAFP-treated A. flavus, but changes in neither $\mathrm{G}$ protein complex $\alpha$ subunit GpaA/FadA nor G protein complex $\beta$ subunit $\mathrm{SfaD}$ were detected. Thus, the relative abundance of the $G$ protein complex $\beta$ subunit $\mathrm{CpcB}$ seems to be the key factor involved in the modulation of apoptotic cell death signals, and the lower amount of this protein could be responsible for the modulating PgAFP toxicity in A. flavus.

Until now, the effect of antifungal proteins from molds has been explained by signaling processes via $G$ protein and RhoA (Binder et al. 2010; Ouedraogo et al. 2011). We propose the lower relative abundance of Rhol and $G$ protein subunit $\beta$ $\mathrm{CpcB}$ to be the main factors in the mode of action of PgAFP. The precise mechanisms responsible for the decrease of these proteins, either by a higher degradation or a decreased biosynthesis, cannot be established at present.

In addition, several proteins involved in the biosynthesis of secondary metabolites were found at lower relative abundance in PgAFP-treated samples. This fact seems to be related to the reduced metabolic hyphae activity revealed with FUN-1 staining (Fig. 2). The suppression of non-essential functions, such as biosynthesis of secondary metabolites, could be explained by the lack of energy due to the described shortage of proteins related to energy metabolism. Among the secondary metabolites produced by $A$. flavus, the hepatocarcinogenic aflatoxins are of utmost interest (Kim et al. 2008). The proteomic analysis did not detect aflK/vbs/VERB synthase and AflM/ver-1/ dehydrogenase/ketoreductase following PgAFP treatment, which are essential enzymes in key steps for aflatoxin synthesis in A. flavus and Aspergillus parasiticus (Yu et al. 2004). Additionally, glutathione S-transferase was found in lower quantities in PgAFP-treated samples. A higher activity of this protein was always associated with increased aflatoxin production in A. flavus (Saxena et al. 1988) and A. parasiticus (Allameh et al. 2002). These results suggest that aflatoxin production is likely to be delayed in PgAFP-treated A. flavus. Despite these results having been obtained in an incubation time of only $24 \mathrm{~h}$, the lack of enzymes essential for aflatoxin 
biosynthesis together with the slower hyphae development could delay aflatoxin production in a longer incubation time. On the other hand, oxidative stress has been shown to stimulate aflatoxin biosynthesis in A. parasiticus (Jayashree and Subramanyan 2000; Reverberi et al. 2005). Due to the induction of ROS by PgAFP, the impact of this antifungal protein on aflatoxin biosynthesis enzymes and also on aflatoxin production will require additional studies.

In conclusion, the mode of action of PgAFP seems to be multifactorial implying membrane changes, reduced metabolic activity, and intracellular ROS production. The changes in the proteins that favor a higher GSH concentration and the increase in heat shock proteins by A. flavus do not seem to be enough to avoid apoptosis. There is also a depression of proteins involved in the biosynthesis of secondary metabolites, including aflatoxin. However, further investigations are required to discern the effect of PgAFP on aflatoxin production prior to the use of this protein to control toxigenic molds.

Acknowledgments This work was supported by the Spanish Ministry of Education and Science, Ministry of Economy and Competitiveness, and FEDER (AGL2010-21623, AGL2013-45729-P). Josué Delgado was a recipient of a FPI grant from the Spanish Ministry of Education and Science (BES-2011-043422 y EEBB-I-13-06900). Rebecca A. Owens was funded by a 3U Partnership Award (http://www.3UPartnership.ie/). Mass spectrometry facilities were funded by Science Foundation Ireland (Q-Exactive; 12/RI/2346(3) and PI/11/1188) and the Irish Higher Education Authority (Agilent Ion Trap 6340).

Conflict of interest The authors declare that they have no competing interests.

\section{References}

Acosta R, Rodríguez-Martín A, Martín A, Núñez F, Asensio MA (2009) Selection of antifungal protein-producing molds from dry-cured meat products. Int J Food Microbiol 135:39-46. doi:10.1016/j. ijfoodmicro.2009.07.020

Agaphonov MO, Packeiser AN, Chechenova MB, Choi ES, TerAvanesyan MD (2001) Mutation of the homologue of GDPmannose pyrophosphorylase alters cell wall structure, protein glycosylation and secretion in Hansenula polymorpha. Yeast 18:391-402. doi:10.1002/yea.678

Allameh A, Razzaghi Abyane M, Shams M, Rezaee MB, Jaimand K (2002) Effects of neem leaf extract on production of aflatoxins and activities of fatty acid synthetase, isocitrate dehydrogenase and glutathione S-transferase in Aspergillus parasiticus. Mycopathologia 154:79-84

Batta G, Barna T, Gáspári Z, Sándor S, Kövér KE, Binder U, Sarg B, Kaiserer L, Chhillar AK, Eigentler A, Leiter E, Hegedüs N, Pócsi I, Lindner H, Marx F (2009) Functional aspects of the solution structure and dynamics of PAF-a highly-stable antifungal protein from Penicillium chrysogenum. FEBS J 276:2875-2890. doi:10.1111/j. 1742-4658.2009.07011.x

Bernáldez V, Rodríguez A, Martín A, Lozano D, Córdoba JJ (2014) Development of a multiplex qPCR method for simultaneous quantification in dry-cured ham of an antifungal-peptide Penicillium chrysogenum strain used as protective culture and aflatoxin- producing moulds. Food Control 36:257-265. doi:10.1016/j. foodcont.2013.08.020

Binder U, Oberparleiter C, Meyer V, Marx F (2010) The antifungal protein PAF interferes with PKC/MPK and cAMP/PKA signalling of Aspergillus nidulans. Mol Microbiol 75:294-307. doi:10.1111/j. 1365-2958.2009.06936.x

Bormann C, Baier D, Hörr I, Raps C, Ho I (1999) Characterization of a novel, antifungal, chitin-binding protein from Streptomyces tendae Tü901 that interferes with growth polarity. J Bacteriol 181:74217429

Bukau B, Horwich AL (1998) The Hsp70 and Hsp60 chaperone machines. Cell 92:351-366

Byczkowska A, Kunikowska A, Kaźmierczak A (2012) Determination of ACC-induced cell-programmed death in roots of Vicia faba ssp. minor seedlings by acridine orange and ethidium bromide staining. Protoplasma 250:121-128. doi:10.1007/s00709-012-0383-9

Cabiscol E, Piulats E, Echave P, Herrero E, Ros J (2000) Oxidative stress promotes specific protein damage in Saccharomyces cerevisiae. J Biol Chem 275:27393-27398. doi:10.1074/jbc.M003140200

Cagas SE, Jain MR, Li H, Perlin DS (2011) Profiling the Aspergillus fumigatus proteome in response to caspofungin. Antimicrob Agents Chemother 55:146-154. doi:10.1128/AAC.00884-10

Carberry S, Neville CM, Kavanagh KA, Doyle S (2006) Analysis of major intracellular proteins of Aspergillus fumigatus by MALDI mass spectrometry: identification and characterisation of an elongation factor $1 \mathrm{~B}$ protein with glutathione transferase activity. Biochem Biophys Res Commun 341:1096-1104. doi:10.1016/j.bbrc.2006. 01.078

Carpentier SC, Witters E, Laukens K, Deckers P, Swennen R, Panis B (2005) Preparation of protein extracts from recalcitrant plant tissues: an evaluation of different methods for two-dimensional gel electrophoresis analysis. Proteomics 5:2497-2507. doi:10.1002/pmic. 200401222

Chen Z, Ao J, Yang W, Jiao L, Zheng T, Chen X (2013) Purification and characterization of a novel antifungal protein secreted by Penicillium chrysogenum from an Arctic sediment. Appl Microbiol Biotechnol 97:10381-10390. doi:10.1007/s00253-0134800-6

Coca MA, Damsz B, Yun DJ, Hasegawa PM, Bressan RA, Narasimhan ML (2000) Heterotrimeric G-proteins of a filamentous fungus regulate cell wall composition and susceptibility to a plant $\mathrm{PR}-5$ protein. Plant J 22:61-69

Collins C, Keane TM, Turner DJ, O'Keeffe G, Fitzpatrick DA, Doyle S (2013) Genomic and proteomic dissection of the ubiquitous plant pathogen, Armillaria mellea: toward a new infection model system. J Proteome Res 12:2552-2570. doi:10.1021/pr301131t

Cox J, Mann M (2008) MaxQuant enables high peptide identification rates, individualized p.p.b.-range mass accuracies and proteomewide protein quantification. Nat Biotechnol 26:1367-1372. doi:10. 1038/nbt.1511

Delgado J, Acosta R, Rodríguez-Martín A, Bermúdez E, Núñez F, Asensio MA (2015) Growth inhibition and stability of PgAFP from Penicillium chrysogenum against fungi common on dry-ripened meat products. Int J Food Microbiol 205:23-29. doi:10.1016/j. ijfoodmicro.2015.03.029

Dolan SK, Owens RA, O'Keeffe G, Hammel S, Fitzpatrick DA, Jones GW, Doyle S (2014) Regulation of non-ribosomal peptide synthesis: bis-thiomethylation attenuates gliotoxin biosynthesis in Aspergillus fumigatus. Chem Biol 21:999-1012. doi:10.1016/j.chembiol.2014. 07.006

Fischer R, Zekert N, Takeshita N (2008) Polarized growth in fungiinterplay between the cytoskeleton, positional markers and membrane domains. Mol Microbiol 68:813-826. doi:10.1111/j.13652958.2008.06193.x

Fuchs BB, Mylonakis E (2009) Our paths might cross: the role of the fungal cell wall integrity pathway in stress response and cross talk 
with other stress response pathways. Eukaryot Cell 8:1616-1625. doi:10.1128/EC.00193-09

Galgóczy L, Kovács L, Karácsony Z, Virágh M, Hamari Z, Vágvölgyi C (2013) Investigation of the antimicrobial effect of Neosartorya fischeri antifungal protein (NFAP) after heterologous expression in Aspergillus nidulans. Microbiology 159:411-419. doi:10.1099/mic. 0.061119-0

Gauci VJ, Wright EP, Coorssen JR (2011) Quantitative proteomics: assessing the spectrum of in-gel protein detection methods. J Chem Biol 4:3-29. doi:10.1007/s12154-010-0043-5

Gautam P, Shankar J, Madan T, Sirdeshmukh R, Sundaram CS, Gade WN, Basir SF, Sarma PU (2008) Proteomic and transcriptomic analysis of Aspergillus fumigatus on exposure to amphotericin B. Antimicrob Agents Chemother 52:4220-4227. doi:10.1128/AAC. 01431-07

Görg A, Drews O, Lück C, Weiland F, Weiss W (2009) 2-DE with IPGs. Electrophoresis 30(Supp1 1):S122-S132. doi:10.1002/elps. 200900051

Guest GM, Lin X, Momany M (2004) Aspergillus nidulans RhoA is involved in polar growth, branching, and cell wall synthesis. Fungal Genet Biol 41:13-22. doi:10.1016/j.fgb.2003.08.006

Hagen S, Marx F, Ram AF, Meyer V (2007) The antifungal protein AFP from Aspergillus giganteus inhibits chitin synthesis in sensitive fungi. Appl Environ Microbiol 73:2128-2134. doi:10.1128/AEM. 02497-06

Hamann A, Brust D, Osiewacz HD (2008) Apoptosis pathways in fungal growth, development and ageing. Trends Microbiol 16:276-283. doi:10.1016/j.tim.2008.03.003

Harris SD, Morrell JL, Hamer JE (1994) Identification and characterization of Aspergillus nidulans mutants defective in cytokinesis. Genetics 532:517-532

Hegedus N, Leiter E, Kovács B, Tomori V, Kwon N-J, Emri T, Marx F, Batta G, Csernoch L, Haas H, Yu J-H, Pócsi I (2011) The small molecular mass antifungal protein of Penicillium chrysogenum - a mechanism of action oriented review. J Basic Microbiol 51:561571. doi:10.1002/jobm.201100041

Hernández-Rodríguez Y, Hastings S, Momany M (2012) The septin AspB in Aspergillus nidulans forms bars and filaments and plays roles in growth emergence and conidiation. Eukaryot Cell 11:311323. doi:10.1128/EC.05164-11

Jayashree T, Subramanyan C (2000) Oxidative stress as a prerequisite for aflatoxin production by Aspergillus parasiticus. Free Radic Biol Med 29:981-985

Jiang H, Ouyang H, Zhou H, Jin C (2008) GDP-mannose pyrophosphorylase is essential for cell wall integrity, morphogenesis and viability of Aspergillus fumigatus. Microbiology 154:2730-2739. doi: 10.1099/mic.0.2008/019240-0

Kabani M, Martineau CN (2008) Multiple hsp70 isoforms in the eukaryotic cytosol: mere redundancy or functional specificity? Curr Genomics 9:338-348. doi:10.2174/138920208785133280

Kaiserer L, Oberparleiter C, Weiler-Görz R, Burgstaller W, Leiter E, Marx F (2003) Characterization of the Penicillium chrysogenum antifungal protein PAF. Arch Microbiol 180:204-210. doi:10. 1007/s00203-003-0578-8

Kaur H, Kumar C, Junot C, Toledano MB, Bachhawat AK (2009) Dug1p is a Cys-Gly peptidase of the $\gamma$-glutamyl cycle of Saccharomyces cerevisiae and represents a novel family of Cys-Gly peptidases. J Biol Chem 284:14493-14502. doi:10.1074/jbc.M808952200

Kim JH, Yu J, Mahoney N, Chan KL, Molyneux RJ, Varga J, Bhatnagar D, Cleveland TE, Nierman WC, Campbell BC (2008) Elucidation of the functional genomics of antioxidant-based inhibition of aflatoxin biosynthesis. Int J Food Microbiol 122:49-60. doi:10.1016/j. ijfoodmicro.2007.11.058

Kovács L, Virágh M, Takó M, Papp T, Vágvölgyi C, Galgóczy L (2011) Isolation and characterization of Neosartorya fischeri antifungal protein (NFAP). Peptides 32:1724-1731. doi:10.1016/j.peptides. 2011.06.022

Lacadena J, Martínez del Pozo A, Lacadena V, Martínez-Ruiz A, Mancheño JM, Oñaderra M, Gavilanes JG (1998) The cytotoxin $\alpha$-sarcin behaves as a cyclizing ribonuclease. FEBS Lett 424:4648. doi:10.1016/S0014-5793(98)00137-9

Lamarre C, Sokol S, Debeaupuis JP, Henry C, Lacroix C, Glaser P, Coppée JY, François JM, Latgé JP (2008) Transcriptomic analysis of the exit from dormancy of Aspergillus fumigatus conidia. BMC Genomics 9:417. doi:10.1186/1471-2164-9-417

Leiter É, Szappanos H, Oberparleiter C, Kaiserer L, Csernoch L, Pusztahelyi T, Emri T, Pócsi I, Salvenmoser W, Marx F (2005) Antifungal protein PAF severely affects the integrity of the plasma membrane of Aspergillus nidulans and induces an apoptosis-like phenotype. Antimicrob Agents Chemother 49:2445-2453. doi:10. 1128/AAC.49.6.2445

Lessing F, Kniemeyer O, Wozniok I, Loeffler J, Kurzai O, Haertl A, Brakhage AA (2007) The Aspergillus fumigatus transcriptional regulator AfYap1 represents the major regulator for defense against reactive oxygen intermediates but is dispensable for pathogenicity in an intranasal mouse infection model. Eukaryot Cell 6:2290-2302. doi:10.1128/EC.00267-07

Levin DE (2005) Cell wall integrity signaling in Saccharomyces cerevisiae. Microbiol Mol Biol Rev 69:262-291. doi:10.1128/ MMBR.69.2.262

Lindsey R, Cowden S, Hernández-Rodríguez Y, Momany M (2010) Septins AspA and AspC are important for normal development and limit the emergence of new growth foci in the multicellular fungus Aspergillus nidulans. Eukaryot Cell 9:155-163. doi:10. 1128/EC.00269-09

Liu R, Huang H, Yang Q, Liu W-Y (2002) Purification of $\alpha$-sarcin and an antifungal protein from mold (Aspergillus giganteus) by chitin affinity chromatography. Protein Expr Purif 25:50-58. doi:10.1006/ prep. 2001.1608

Lockington RA, Borlace GN, Kelly JM (1997) Pyruvate decarboxylase and anaerobic survival in Aspergillus nidulans. Gene 191:61-67

Lowry OH, Rosebrough NJ, Farr L, Randall RJ (1951) Protein measurement with the folin phenol reagent. J Biol Chem 193:265-275

Luber CA, Cox J, Lauterbach H, Fancke B, Selbach M, Tschopp J, Akira S, Wiegand M, Hochrein H, O'Keeffe M, Mann M (2010) Quantitative proteomics reveals subset-specific viral recognition in dendritic cells. Immunity 32:279-289. doi:10.1016/j.immuni.2010. 01.013

Marx F (2004) Small, basic antifungal proteins secreted from filamentous ascomycetes: a comparative study regarding expression, structure, function and potential application. Appl Microbiol Biotechnol 65: 133-142. doi:10.1007/s00253-004-1600-z

Marx F, Binder U, Leiter E, Pócsi I (2008) The Penicillium chrysogenum antifungal protein $\mathrm{PAF}$, a promising tool for the development of new antifungal therapies and fungal cell biology studies. Cell Mol Life Sci 65:445-454. doi:10.1007/s00018-007-7364-8

Marx F, Haas H, Reindl M, Stöffler G, Lottspeich F, Redl B (1995) Cloning, structural organization and regulation of expression of the Penicillium chrysogenum paf gene encoding an abundantly secreted protein with antifungal activity. Gene 167:167-171

Moreno AB, Martínez Del Pozo A, San Segundo B (2006) Biotechnologically relevant enzymes and proteins. Antifungal mechanism of the Aspergillus giganteus AFP against the rice blast fungus Magnaporthe grisea. Appl Microbiol Biotechnol 72:883895. doi:10.1007/s00253-006-0362-1

Nakaya K, Omata K, Okahashi I, Nakamura Y, Kilkenbrock H, Ulbrich N (1990) Amino acid sequence and disulfide bridges of an antifungal protein isolated from Aspergillus giganteus. Eur J Biochem 193:3138

O'Keeffe G, Hammel S, Owens RA, Keane TM, Fitzpatrick DA, Jones GW, Doyle S (2014) RNA-seq reveals the pan-transcriptomic 
impact of attenuating the gliotoxin self-protection mechanism in Aspergillus fumigatus. BMC Genomics 15:894. doi:10.1186/14712164-15-894

O’Keeffe G, Jöchl C, Kavanagh K, Doyle S (2013) Extensive proteomic remodeling is induced by eukaryotic translation elongation factor 1B $\gamma$ deletion in Aspergillus fumigatus. Protein Sci 22:1612-1622. doi: $10.1002 /$ pro. 2367

Oberparleiter C, Kaiserer L, Haas H, Ladurner P, Andratsch M, Marx F (2003) Active internalization of the Penicillium chrysogenum antifungal protein PAF in sensitive Aspergilli. Antimicrob Agents Chemother 47:3598-3601. doi:10.1128/AAC.47.11.3598

Ouedraogo JP, Hagen S, Spielvogel A, Engelhardt S, Meyer V (2011) Survival strategies of yeast and filamentous fungi against the antifungal protein AFP. J Biol Chem 286:13859-13868. doi:10.1074/ jbc.M110.203588

Owens RA, Hammel S, Sheridan KJ, Jones GW, Doyle S (2014) A proteomic approach to investigating gene cluster expression and secondary metabolite functionality in Aspergillus fumigatus. PLoS One 9:e106942. doi: 10.1371/journal.pone.0106942

Penninckx MJ (2002) An overview on glutathione in Saccharomyces versus non-conventional yeasts. FEMS Yeast Res 2:295-305

Rabilloud T, Vaezzadeh AR, Potier N (2009) Power and limitations of electrophoretic. Mass Spectrom Rev 28:816-843. doi:10.1002/mas

Reverberi M, Fabbri AA, Zjalic S, Ricelli A, Punelli F, Fanelli C (2005) Antioxidant enzymes stimulation in Aspergillus parasiticus by Lentinula edodes inhibits aflatoxin production. Appl Microbiol Biotechnol 69:207-215. doi:10.1007/s00253-005-1979-1

Rodríguez-Martín A, Acosta R, Liddell S, Núñez F, Benito MJ, Asensio MA (2010) Characterization of the novel antifungal protein PgAFP and the encoding gene of Penicillium chrysogenum. Peptides 31 : 541-547. doi:10.1016/j.peptides.2009.11.002
Saxena M, Mukerji KG, Raj HG (1988) Positive correlation exists between glutathione S-transferase activity and aflatoxin formation in Aspergillus flavus. Biochem J 254:567-570

Shevchenko A, Tomas H, Havlis J, Olsen JV, Mann M (2006) In-gel digestion for mass spectrometric characterization of proteins and proteomes. Nat Protoc 1:2856-2860. doi:10.1038/nprot.2006.468

Slater AFG, Stefan C, Nobel I, Van den Dobbelsteen DJ, Orrenius S (1995) Signalling mechanisms and oxidative stress in apoptosis. Toxicol Lett 82(83):149-153

Squier TC (2001) Oxidative stress and protein aggregation during biological aging. Exp Gerontol 36:1539-1550

Theis T, Wedde M, Meyer V, Stahl U (2003) The antifungal protein from Aspergillus giganteus causes membrane permeabilization. Antimicrob Agents Chemother 47:588-593. doi:10.1128/AAC.47. 2.588

Theis T, Marx F, Salvenmoser W, Stahl U, Meyer V (2005) New insights into the target site and mode of action of the antifungal protein of Aspergillus giganteus. Res Microbiol 156:47-56. doi:10.1016/j. resmic.2004.08.006

Thevissen K, Ghazi A, De Samblanx GW, Brownlee C, Osborn RW, Broekaert WF (1996) Fungal membrane responses induced by plant defensins and thionins. J Biol Chem 271: $15018-15025$

Thevissen K, Terras FR, Broekaert WF (1999) Permeabilization of fungal membranes by plant defensins inhibits fungal growth. Appl Environ Microbiol 65:5451-5458

Yu J, Chang P, Ehrlich KC, Cary JW, Bhatnagar D, Cleveland TE, Payne GA, Linz JE, Woloshuk CP, Bennett W, Bennett JW (2004) Clustered pathway genes in aflatoxin biosynthesis. Appl Environ Microbiol 70:1253-1262. doi:10.1128/AEM.70. 3.1253 